\title{
Define “Social Exclusion”, Articulate Realistic Benchmarks and Evaluation Modalities for the Livelihood Empowerment against Poverty Program, Ghana
}

\author{
Ishmael Norman $1,2,3$ \\ ${ }^{1}$ School of Public Health (Hohoe Campus), University of Health and Allied Sciences, Ho, Ghana \\ ${ }^{2}$ Institute for Security, Disaster and Emergency Studies Sandpiper Place, Langma, Ghana \\ ${ }^{3}$ African Academy for Environmental Health (AAEH), University of Malawi, Blantyre, Malawi \\ Email:ishmael_norman@yahoo.com
}

How to cite this paper: Norman, I. (2017). Define "Social Exclusion", Articulate Realistic Benchmarks and Evaluation Modalities for the Livelihood Empowerment against Poverty Program, Ghana. Advances in Applied Sociology, 7, 16-34.

http://dx.doi.org/10.4236/aasoci.2017.71002

Received: August 22, 2016

Accepted: January 22, 2017

Published: January 25, 2017

Copyright $\odot 2017$ by author and Scientific Research Publishing Inc. This work is licensed under the Creative Commons Attribution International License (CC BY 4.0).

http://creativecommons.org/licenses/by/4.0/

\begin{abstract}
The Livelihood Empowerment Against Poverty, a "flagship" program of Ghana, has been praised as a Sub-Saharan Africa's "miracle cure" for poverty alleviation because it gives US $\$ 4.00-6.00$ a month to a single beneficiary household. In any other regions of the world, the paltry sum would not be praiseworthy. This paper reviewed the literature on the Livelihood Empowerment Against Poverty program to identify the reported gains by beneficiaries. Using government's own publication on LEAP, the author sought to determine evidence of exclusion of the extreme poor, and to find if the alleged gains under LEAP have improved the social inclusion and functionings of the beneficiary households by reducing the alleged social exclusion, chronic poverty and deprivation or by improving social solidarity and equal opportunities for the beneficiaries. Internet search of pertinent literature was conducted, with hand searching of grey literature produced by the Ghana Ministry of Women and Children Affairs and others on the matter. The pertinent papers that addressed the research questions were read and briefed for analyses. The published literature reveals that the program has not significantly improved the capabilities, functionings and being of beneficiaries, though there is a plethora of anecdotal reportage about improvements in their lives. In rural Ghana poverty is not the basis for social exclusion, though disability is. The loose eligibility criteria reward undeserving recipients of LEAP. The government of Ghana and its development partners need to conduct monitoring and evaluation exercise of the program to assess the contributions, if any. They also need to have a working definition of social exclusion, social isolation and solidarity in order to identify the types of exclusions that should inform
\end{abstract}


policy and intervention. There is an urgent need to redesign the program, rearticulate the eligibility criteria and to set clear pathways for capacity building of the beneficiary household leaders towards productive activities.

\section{Keywords}

Livelihood, Empowerment, Poverty and Deprivation, Social Exclusion, Social Solidarity, Capability, Functionings, Equal Opportunity, Ghana

\section{Introduction}

It seems when it comes to the assessment of Sub-Saharan Africa's performance, any result from international or national programs with defined or ill-defined, and with or without benchmarks for program monitoring and evaluation is praiseworthy (Handa et al., 2013). However, the same performance from Asia or South or Central America of similar programs would probably not receive any sort of positive endorsement, because a lot more is expected of these other nations. Such double standard is not only condescending but acts as disincentive to Sub-Saharan Africa generally speaking. It is a disservice to its people (Schaefer, 2003; Van de Walle, 2001). An international case in point is the confusing MDG 2015 outcome report on Ghana. Reading through the Ghana Millennium Development Goals Report of 2015, a program which is touted universally as a success, gives one a true Kantian feeling of satisfaction and pleasure that Ghana with Sub-Saharan Africa, (SSA) is transcending its development challenges. That the region is reducing extreme poverty and improving general homeland security indicators for the benefit of those considered to be extremely poor. By so doing, enhancing the overall health status of the nation is consistent with the social development advocacy of many a researchers and experts. Some of these indicators include access to healthcare, availability of essential drugs to the enrolees of the National Health Insurance Scheme, reduction in the under 5-year old mortality and morbidity from malaria, diarrhoea and other diseases, and overall improvement in the economic and social determinants of health (Ghana Health Service Annual Report, 2010; 2011; 2012; 2013; 2015). Not only that, but that the region is even prevailing beyond the wildest collective imaginations of the nationals themselves (Ghana/UNDP MDG Report, 2015: p. 1). A national case in point is the government sponsored report authored by Handa et al., (2013). This evaluative report has been cited as the supporting evidence of the success of the government's LEAP program, even though the report actually stopped short of making such a claim. On similar lines, the World Bank recently commended Ghana as a success story in terms of poverty alleviation because of LEAP. "To the bank, Ghana as a middle income country was the first in Sub-Saharan Africa to achieve the Millennium Development Goal (MDG) No. 1 of reducing poverty and hunger ahead of the deadline of 2015" (Kulyk, 2015).

How did this happen and which part of Ghana did this wonderful develop- 
ment happen, if, in fact, it is translational in the lives of the citizens? The performance of the overall economy of Ghana is so bad that statistical correlations are incapable of describing the reality of the hardships the people face daily. There has been reported increases in personal and business loan and mortgage default rates and closures in the manufacturing base of the nation. Per data produced by the Ghana Statistical Service, manufacturing base in Ghana has seen bad times, with percentage growth rates in (Manufacturing) at $-1.3 \%$ (2009); 7.6\% (2010); $17.0 \%$ (2011); $2.0 \%$ (2012); 0.6\% (2013) and 0.5\% (2014) respectively (Association of Ghana Industries, 2015; Ghana Statistical Service, Gross Domestic Product, 2014:6). What is interesting is that in the same MDG 2015 country report, the World Bank appears to echo the same concern that, "the challenge in Ghana was how to translate its achievements as stated in the official MDG report, which is on statistics to the people, adding that the situation on the ground was "far from mission accomplished" (Kulyk, 2015).

If you are an incurable optimist and believe that SSA is progressing up and up, fair enough. The realities contained in the same report, however, give a more discerning reader the opportunity to be circumspect in appraising the progress made in SSA under the MDGs. For example, when one reads the below quotation, one is tempted to ask, where is the evidence?

"The world has seen remarkable progress since the adoption of the MDGs about a decade and a half ago. Hundreds of millions of people have been lifted out of extreme poverty and immense gains recorded in key indicators of social development (Ghana/UNDP, 2015)" ... "All regions except SSA were able to reduce the incidence of extreme poverty between 1990 and 2011 by 50 percent or more. The incidence of extreme poverty in SSA declined over a period of two decades from 56 percent in 1990 to 48 percent in 2010 (Ghana/UNDP, 2015)”.

As one keeps reading the report and looking at the goals and gains on item by item basis, such as sanitation, education, women empowerment, to mention but a few, one notices that; perhaps; there is too much of "much ado about nothing", to borrow from William Shakespeare. When it comes to sanitation practices or the lack of it in Ghana and elsewhere in SSA, it would perhaps, be repetitive to reproduce the litany of cases and statistics of cholera and malaria morbidity and mortalities. The pessimist might say that Sub-Saharan Africa is at where it was prior the commencement of the MDGs. It is possible to accept that some improvements have occurred, but the effect appears to be so marginal that substantively, it does not make much of a difference to the reality on the ground. In fact; in some cases some of the nations in SSA are worse off. For example:

"Southern Asia and sub-Saharan Africa (SSA) account for more than half of the world's vulnerable employment, with three out of four workers falling into this category. The rate of vulnerable employment in SSA declined by 1.7 percent percentage points over 2003-2008 and slowed down even further after the 2008 financial crisis. Women were more likely to be engaged 
in vulnerable employment in all regions. In 2013, an estimated 85 percent of women in SSA were in vulnerable employment compared to 70 percent of men (Ghana/UNDP MDG Report, 2015: p. 3)”.

By vulnerable employment, it is meant self-employment. It also means that the worker has not been able to employ anyone else in the business. In a region or nation where gainfully employed workers, to borrow a local expression, "cannot see top", it is doubtful if the $85 \%$ of women engaged in vulnerable employment are not actually engaged in marginally rewarding jobs. What that data tells of women's opportunities and participation in the respective economies is that, there is a systemic exclusion of women in well-paying jobs. The only choice left, short of doing nothing, waste away, is to engage in "pretend" jobs, like scores of women selling tomatoes or smoked fish in head pans on the same route or place and next to each other, with marginal to zero returns.

Again, one is left with troubling questions when the alleged gains are viewed in the context of the nation's debt burden. The debt burden of the nation as at May 2015 stood at 89.5 billion Cedis which is $67.1 \%$ of Gross Domestic Product (GDP). In April, 2016 the country's total debt stock stood at 88.1 billion Cedis, representing $66.1 \%$ of GDP (Bank of Ghana Report, 2016). During this time, employment opportunities also were limited, especially for university and college graduates.

"In Ghana, youth employment in 2012, was about 52\% of those aged 15 24 , compared to about $90 \%$ of those in the 25 - 64 cohort. A third of the youth population were in school, while $14 \%$ were inactive and only about $4 \%$ who were unemployed, were actively looking for job. Young women in the same age group were particularly disadvantaged and had much higher inactivity rates than males with $17 \%$ of the young female being inactive as opposed to $11 \%$ of males", (World Bank/Bank of Ghana Report: “The Landscape of Jobs in Ghana", 2016).

Graduate unemployment is likely to climb to more than 271,000 this year from the current 200,000 (Amankrah; Centre for Economic Policy Analysis (CEPA), 2016).

Mistakes and Errors Appraising National Economic Woes by Supranational Entities

Recently, the World Bank and the IMF admitted that their calculation and appraisal of risk, liquidity and monetary policy of the European Union had been wrong (IMF: Independent Evaluation Office (IEO), 2016). The London Telegraph Newspaper report also offered that "the International Monetary Fund's top staff misled their own board, made a series of calamitous mis-judgments in Greece, became euphoric cheerleaders for the Euro project, ignored warning signs of impending crisis, and collectively failed to grasp an elemental concept of currency theory" (Pritchard, London Telegraph, 2016). And that, they had wrongfully ascribed the problems of the EU to Greece and thereby deepening the worsening conditions of Greece's national economy and liquidity problems. 
Granted, Greece is not Ghana, and the European Union, (EU) is not the African Union, (AU). However, could it be that years to come, these same institutions are going to re-triangulate their data on the progress of Sub-Saharan Africa under the MDGs, the Sustainable Development Goals, SDGs, and in the case of Ghana, the LEAP program with the admission that they had been wrong for years about SSA's progress or the lack of it under the MDGs, the SDGs or the LEAP program?

\section{A Brief History of the LEAP in Ghana}

The Ghana Livelihood Empowerment Against Poverty, (LEAP) cash transfer program targets extremely poor households with elderly, disabled or orphan and vulnerable children. The payment of between US\$4 to 8 a month is made every two months through a local pay point' (Oxford Policy Management/FAO, 2013). LEAP aims to "empower the poor by enhancing their capacity to access government interventions and to enable them to "LEAP out of poverty" (Ministry of Employment and Social Welfare (MESW), 2007, 2012, 2015). The program is managed by the Ministry of Women and Children's Affairs but being implemented by the Department of Social Welfare (DSW), under MESW. In 2007, LEAP started as a pilot program, under the government of Mr. John A. Kufuor, the New Patriotic Party, a fiscal conservative party with compassionate social policies. The pilot of LEAP was to be studied overtime, collect essential data and tweak the program for scaling nationally. The UK government's development agency, DFID, has been a supportive partner from the beginning but ultimately, the national launching and administration of the program is in the hands of the nationals. At the end of 2008, the New Democratic Congress, under Prof. Evans J. A. Mills took over the new national government after a successful and peaceful general election. It appears that from this period on, somehow, caution was let out of the administration of LEAP and continued to roll out without the apparent epidemiologic considerations at the pilot phase. Soon, however, LEAP reached 1654 beneficiary households in 21 selected districts. By 2012, LEAP was doling out cash payments to 70,191 beneficiaries scattered in 100 districts nationwide. In 2015, some 150,000 beneficiaries (not households) were enrolled in the LEAP program (DSW, 2012; 2015). Enrolees in LEAP were automatically also enrolled in the National Health Insurance Scheme, and were entitled to school uniform subsidy as well as agricultural inputs subsidies. The selection or inclusion criteria of beneficiary household are murky. But beneficiary households were selected based on if there is any of the following factors: the prevalence of adverse health conditions such as high incidence of guinea worm, (a disease which is eradicated from Ghana after a 26 year battle), (GNA, 2015), buruli ulcer and HIV/AIDs. In the list of qualifying diseases, why even end with these few diseases? Why not include the 8000 patients of kidney disease in Ghana, who cannot afford the dialysis treatment of four hours three times a week at the whopping cost of about US\$225.00 a month? Or breast cancer and prostate cancer patients? Why not include men who suffer from erectile dysfunction? Other considerations for selection into LEAP were the prevalence of 
child labour or child trafficking, the lack of access to quality basic social services, and the degree of geographical isolation of the community. Additionally, any other factor which in the considered opinion of the District LEAP Implementation Committee (DLIC) was germane in the assessment was in fact included in the eligibility evaluation.

Unfair eligibility criteria created disparities for LEAP. The underlying disparities embedded in the program continue to persist even after the alleged evaluation of the program by various experts and organizations. According to a report filed by the Ghana News Agency in June, 2016, effective from September, 2016, a single LEAP beneficiary household would receive GH\$64.00 per month or US\$16.00. Two person household would obtain GH\$76.00 or US\$9.50, with three person household receiving GH $\$ 88.00$ or US\$7.30 but a four or more persons' household would get GH\$106.00 or US\$6.50. These payment caps seem to be saying, "the fewer, the merrier", but a universal assistance and benefits program cannot persist with such discriminatory stratification (Tandoh, 2016).

Despite the laudable goal of feeding the extremely poor, the misgivings about the alleged successes of the LEAP programs in the public and among some NGOs and Civil Society Organizations continue to exist. This is because apart from the narrative on the reported success not providing the general public with evidence of success or baseline data on the life of the beneficiary households before participating in LEAP, it is also wasteful and discriminatory. In order to claim intervention program success, it is helpful to revert to the beginning of things, a baseline, before the rolling out of the program.

"Baseline refers to measurements of key conditions (indicators) before a project begins, from which change and progress can be assessed. It helps to set achievable and realistic indicator targets and informs project management decision-making, by providing a reference point to determine progress and adjust project implementation to best serve people in need. It also provides a point of assessment and measurability of the selected indicators and upholds accountability, informs impact evaluation. The specific methodology will depend on a variety of project-specific factors, ranging from specific indicators to time and budget" (IFRC, Planning \& Evaluation Department-May, 2013).

In this instance though, because no such care appears to have been initiated, the gains reported of the LEAP program appear as phantasms of the active imaginations of politicians and stakeholders, who may potentially be facing the threat of project failure, and accountability. The aftermath of such reservations is the suspicion that like the reportage on the MDGs outcomes, the reportage on LEAP would probably contain intentional obfuscation. Immaterial gains would be misrepresented, befuddled, and puffed for political effect or to show that the government is responsive to the needs of those living in extreme poverty. But is this the only way to reduce extreme poverty in Ghana where the underlying economy does not provide confidence to even the most astute business men and 
women? The answer is obviously, no, there are other, more dignified ways.

Dependence on social security benefits itself has a way of becoming entrenched, habitual and could lead to further deterioration of the social fabric or solidarity and protracted dysfunctionality. This is what Ghana may learn from the United States of America's experience:

America's welfare system has served neither the poor nor the taxpayer well. When Lyndon Johnson launched the War on Poverty in the mid-1960s, he intended it to strike "at the causes, not just the consequences of poverty". The aim of that effort was "not only to relieve the symptom of poverty, but to cure it and, above all, to prevent it". President Johnson's goal was not to create a massive system of ever-increasing welfare benefits for an ever-larger number of beneficiaries. Instead, he sought to increase self-sufficiency, enabling recipients to lift themselves up beyond the need for public assistance by "making taxpayers out of tax-eaters". Since then the United States has spent nearly $\$ 20$ trillion on means-tested welfare programs. And while the material living conditions of the poor have improved in that time, dependence on public assistance has only grown" (Rector, 2016).

Other national civil society organizations and NGOs have also expressed doubt about the program's success and sustainability as claimed by government, although intrinsically, the same groups also see the need to develop innovative social programs to alleviate poverty, locus classicus is IMANI-Ghana. IMANI explained its opposition thus,

"The poverty line of $\$ 1.83$ per day and extreme poverty line of $\$ 1.25$ per day, as captured by the Ghana Living Standards Survey 6, translates into 8.4 per cent of the population in extreme poverty, of which LEAP had covered 7.1 per cent by 2015 (150,000 households). The LEAP cash transfers have also resulted in a significant shortfall to protection against the extreme poverty threshold (IMANI-Ghana, 2016)".

It appears the philosophical justification underlying the praise being heaped on Ghana for its LEAP program by the various agents is, perhaps, driven by a condescending, albeit, perhaps, unintended, cultural differences argument. Since poverty is always an issue of location, local conditions influence the discussion immensely. The agency argument goes something like this: If the beneficiaries of LEAP were like me, they would not live on US $\$ 4.00$ a month, when the going universal rate for extreme poverty is about US $\$ 1.25$ a day. I live on, may be, US $\$ 40.00$ a day. Since they are not like me, perhaps, even inferior to me, US\$4.00 a month is good enough and for this paltry sum, Ghana deserves our collective applause as agents of change. After all, LEAP is the government of Ghana's "flagship" social inclusion program designed for its citizens within the context of Ghana (FAO: Ghana Country Case Study Report, 2013)!

In fact, the already measly sum is not paid out as regularly as it is expected. There is also some considerable confusion about what exactly is the value of the cash which is supposed to be paid out. While some reports state US $\$ 1.85$ per 
week others state completely different figures, including US $\$ 4.00$ to 8.00 per month, depending on family size (FAO: Ghana Country Case Study Report, 2013). Over the years, the original sum of entitlement by a household of US $\$ 4.00$ or a larger household of US $\$ 8.00$ has been changed as reported earlier. But working with the original sum, to live on US $\$ 4.00$ a month is still restrictive.

\section{Improving the Functionings of Beneficiary Households of LEAP}

Attention would now be briefly drawn on the issue of capability and functionings of the beneficiary households in the LEAP program. This is necessary because poverty, social exclusion and deprivation are difficult concepts to analysis and with the appropriate interventions developed. In view of this, Amartya Sen's Capability Approach is being employed to offer another way to appraise poverty in the broader context of differential vulnerabilities even among the extremely poor and the disabled or orphans. As part of its goal, LEAP aims to provide economic and social protection to the beneficiary households so that they would be able to "LEAP out of extreme poverty". Even though no blue-print was given as to how the alleged LEAP would or should occur, it may imply that the LEAP program is calibrated to enhance the capabilities and functionings of the beneficiary households. As Peace (2001) concisely put it, such households suffer from the "lack of access to factors such as social mobility, means of communication, vital social systems, housing, public amenities, social security, health services, education services, and social citizenship" (Peace, 2001: p. 23 in Peace 1999: p. 398). There may also be other "personal intensifiers" such as bad choices, bad marriage, drug use or trafficking, as well as spatial intensifiers of "social isolation, geographical isolation and the sense of loneliness" (Peace, p. 2001). In the LEAP program, not much of a list of concerns were articulated and that is why this paper relies so much on other subject experts to identify a way out of this intellectual schism and attempt to fill in the design gaps, and to address the defects as inherent features of the Ghana LEAP program.

In the Capabilities Approach, Sen (1999: p. 75) defines functionings as "the valuable activities and states that become a person's wellbeing, such as a healthy body, being safe, being educated, having a good job, being able to move... Functionings are the various things a person may value doing or being". Since this author could not find any baseline study on the beneficiary household of LEAP, it is difficult to map out what they (beneficiaries) did; particularly those who are currently reported to be undertaking some form of income producing activities. At any rate, Capability refers to the freedom one has to do these valuable activities or reach such valuable states (Sen, 1999; Deneulin \& McGregor, 2009: p. 2). The foregoing calls for the freedom of the beneficiary households in the context of Ghana's LEAP program, to have autonomy and, therefore, the freedom to produce what he or she wants and to be fully human (Deneulin \& McGregor, 2009; Seers, 1969). Since LEAP is also designed to address issues of social exclusion, as well as social justice and social solidarity, it would have helped the discussion if we could have had a glimpse of the lives of the beneficiary households with respect to these social burdens. The LEAP program appears to share a 
common purpose with Sen's Capability Approach in relation to the anticipated drive of LEAP that the beneficiary households would pursue their dreams with the aid of government cash interventions. The author would investigate if the beneficiary households are, in fact, focused on such a goal, and if such a goal is achievable by them, given the limited power and social challenges that extreme poverty may impose on people.

\section{Method}

\section{The internet and Hand Search Strategy:}

The author searched databases such as PubMed, Medline and others for reports, editorials and published papers in the English Language. A search on Goggle Scholar on "the livelihood Empowerment against Poverty" yielded over 200,000 entries and "Pro-poor programs in Ghana" yielded close to 470,000 with "Sanitary pads for school girls in Ghana" yielding over 130,000 entries. Additional Internet search was conducted, with hand searching of grey literature produced by the Ghana Ministry of Women and Children Affairs and others. Internet search combinations such as "Progress of LEAP beneficiaries"; "Capability enhancement by LEAP" (370,000 entries); "Cash value of LEAP pay out" (6600 entries); and "Delays in LEAP payments" (850,000 entries) were used. Other combinations were "Social Exclusion in Ghana" (400,000 entries); "Social Solidarity"; "Social Justice"; and "Poverty and Deprivation in Ghana" (over 400,000 entries).

The search was broken into three main thematic areas to assess the capabilities and functionings of the beneficiaries of the LEAP program. The themes were selected based on the themes used by the government of Ghana and as stated in the Ghana/DFID/FAO Ghana Country Report of 2015, namely: Household economy, Local economy impacts and Social Networks and Complimentary Services such as co-opting the beneficiaries into the National Health Insurance Scheme, provision of School uniforms for the children and ward of the beneficiaries and the provision of Agricultural inputs. The paper also sought to validate the assertion underlying the LEAP program that due to extreme poverty, there is social exclusion, social isolation and the lack of solidarity within the context of the local culture and practices and in relation to the poor, aged, people with physical disabilities and the generally marginalized.

Inclusion and Exclusion Criteria for the Assessment of Effects:

The author adopted strict inclusion criteria for the papers reviewed for this article. A searched of newspapers was conducted to assess reports of progress or otherwise on LEAP. As much as (86) Eighty-six publications that met the inclusion criteria out of over 500,000 articles, opinions, blogs, grey literature and policy documents were reviewed, briefed and re-analysed for this paper, when saturation was reached. Each paper was assigned an overall score. A score of: $1=$ Entirely Relevant (ER); 1/2 = Somewhat Relevant (SR); and $0=$ Not Relevant at All, $(\mathrm{NRaA})$ against the themes used in this paper as adopted from government's program goals. The selected papers were rated and the papers that received 
scores above 2.5 out of 4 in this evaluation were further analysed. The findings were summarized into their respective units, and interpreted them based upon the author's skills and knowledge in ethics, policy, sociology, public health and law. The author excluded papers and reports that did not provided empirical data on activities associated with LEAP. In addition, Epidemiological investigation into any of the themes contained in this paper was not conducted but relied on existing literature.

The Approach Adopted for the Paper:

Although the author selected the themes for this paper based on the themes used by the government of Ghana and as stated in the Ghana/DFID/FAO Ghana Country Report of 2015, (namely: Household economy, Local economy impacts and Social Networks and Complimentary Services such as co-opting the beneficiaries into the National Health Insurance Scheme, provision of School uniforms for the children and ward of the beneficiaries and the provision of Agricultural inputs), the focus was primarily on the effects of the beneficiary households on the local economy as auxiliary goal for the "local economy". The following are the reasons this approach was adopted:

First, the published literature did not provide impact analyses of the household economy on the local economy. Perhaps, because there was no baseline data to be triangulated for impact analyses, the hired agents of government did not also conduct deep analyses of the effect or impact of LEAP on the local economy, but provided cursory and, in some cases, simulative impact information. For example in an impact analyses study produced by FAO, UNICEF and Ghana's Institute of Statistical Social and Economic Research, ISSER under the title: Local Economy-wide Impact Evaluation (LEWIE) of Ghana's Livelihood Empowerment Against Poverty (LEAP) program (2014), there was only a simulative result of the multiplier effect of LEAP on the local economy, thus:

"The LEWIE model simulation showed that the LEAP programme has a potential total income multiplier of GHS 2.50 in nominal terms, with a 90 percent confidence interval (CI) of 2.38 - 2.65. That is, each cedi transferred to poor households can raise local income by GHS 2.50 .

However, if supply constraints are binding-that is, if local production or supplies of goods do not increase sufficiently to meet the increased demand brought on by the cash transfer-then the result can be upward pressure on prices. This would raise consumption costs for all households and could result in a real-income multiplier that is lower than the nominal multiplier. According to the LEAP LEWIE, this real income multiplier of the programme could be as low as GHS 1.50 (CI: 1.40 - 1.59)".

The above write-up reads like baseline material and not an evaluation of a program that has run since 2007, seven years before the FAO, UNICEF and ISSER's LEWIE model simulation! This author considered the statements on the local economy found in the literature as mere hearsays, for want of a better word, and not empirical or scientific evaluation of the historical performance 
record of LEAP, and so did not include such studies in this review to demonstrate impact or effect. This is because this paper is not about what could happen in the future (as this simulation data appears to be about) but what has already happened (which is more of forensic investigation of existing, historical data) to have improved (already) the local economy after 2007 LEAP cash injection. In the future, all things are actually possible, including, perhaps, turning LEAP beneficiaries into multi-billionaires.

Secondly, there was no evidence of what the government had actually done in furtherance of the stated associated aims of LEAP such as how many actual beneficiary households were provided with, for example, agricultural farm inputs, or school uniforms. In Ghana elementary schools pupils tend to be provided with free books, sometimes even shoes, and uniforms. Sometimes the girl-pupils are supplied with free panty liners for the management of menses irrespective of income or economic status, and irrespective of whether the student comes from a LEAP home or not. Perhaps, because of such national programs, data on LEAP beneficiaries as a cohort is difficult to segregate from the national data-set and this weakness is again, perhaps, due to poor record keeping and recordation, a feature so common with national programs.

Thirdly, the literature revealed cursory treatment of issues such as "Social Networks" with occasional statements of perceived general improvements in the social networks of the beneficiary households. Some of the statements included examples like the following: "beneficiaries were accepted back into their families after receiving the cash transfers". Notice that there was no prior evidence provided to show that the beneficiaries had ever not been part of their households because of poverty.

These three examples are the reasons why, in conducting this review, the author was compelled to discuss only "household economy" in details but provided cursory treatment of "Local economy impacts" and "social networks and complimentary services" and mentioned them in passing. Author did not conduct a strict systematic review, where certain procedures would have happened such as segregating qualitative papers from quantitative ones, stating the phenomenon of interests; and so on, but briefed and reviewed the papers in line with the objectives of this paper.

\section{Result and Discussions}

\section{Social Exclusion, What Does It Mean in the Context of Ghana?}

The definition of social exclusion is contextual (Harvey, 1990; 1994; Silver, 1994; Barry, 1998; Peace, 1999; 2001). Sen (2000) indicated that the historical roots of the concept of social exclusion dates back to the time of Aristotle. Mathieson et al. (2008) reported that in the modern era, it was Rene Lenoir, Secretary of State of Social Action Gaullist government, French, that first popularized the term. However, even in France, the concept dates back to Emile Durkheim's work in 1895. Peace (2001) in his paper tracing the origins of the term, added the dimension that, "exclusion sociale" was not an affirmative ac- 
tion concept (or entitlement concept) as it is made out to mean now, at least, in France. This reading reverts to Rene Lenoir's socialist policy initiative. It was used as a motivating tool to enable people to re-engage in society, especially those who had been down and out and wanted to get back into mainstream social activities like securing gainful employment, marrying to someone who is actually gainfully employed, and so on. Peace wrote that "it is important to know what people were being excluded from and by whom" (Peace, 2001; Estivill, 2003; Levitas, 2005).

"In the case of 'exclusion sociale' the agency was clear. The French Government made policies that excluded particular groups from receiving social insurance (or support) on the basis of explicit criteria. If you wanted to be included amongst those who had access to social insurance you found a job, or you got married to someone who had a job. This was inclusion and exclusion in a definable sense" (Peace, 2001).

It was as Sen had advocated, a way to get people to do "meaningful things" and to be "fully human" (Sen, 1979; 1982; 1987; 1993; 1995; Deneulin and McGregor, 2009).

In the European Union and other parts of the Western Industrialized world, the term has come to mean variously as exclusion from employment (Peace, 2001), from education in the United States of America (Brown vs. Board of Education, 1954; Myrdal, 1944), and equal opportunity in the EU (Madanipour et al. 1998). Brown vs. Board of Education was a seminal case in which the US Supreme court ruled that establishing separate public schools for black and white students was unconstitutional.

In Ghana, the philosophical underpinning of social exclusion appears to be focused purely on entitlement (Bettinger, 1977; Blakely \& Bradshaw, 2002; Blank, 1997; 2003). It seems it is a national attempt to right the wrongs of society against those who live in chronic extreme poverty (Bradshaw \& Muller, 2005; Bradshaw, 2000). It appears to be an apology and acceptance of blame/responsibility on the part of government for creating the conditions for extreme poverty to exist in the first instances (Blank, 1997; 2003; Gough and Eisenschitz, 2006). Again in Ghana, the concept of social exclusion is both dicey and dodgy because the society does not accept that it is stratified, but rather a classless one. The fact is, like any other society it is very much stratified on economic, professional, age, gender, ethnic, political, regional, district, and even sub-district lines (Norman et al, 2016; Norman \& Aviisah, 2015).

Having said this, it is also important to note that in the parochial and agrarian communities of Ghana, there is the amalgamation of the classes irrespective of one's financial standing or value. It is therefore difficult to import social exclusion into this cultural milieu. The conflation of the classes occur at cultural and chieftaincy events and practices, marital rites, funeral rites and community projects. When a young man wants to marry a woman from another family, the clan members of the woman's family and those of the man are consulted, irrespective 
of whether the potential couple is urbanized, educated, or rich, and irrespective of whether the clans men and women are rich or poor, educated or not. Both marginalized and non-marginalized members of the family are consulted even today in our globalized, market oriented world (Norman et al., 2012a; 2012b). It is not unusual to find prominent national figure sitting together with the village linguist or town crier about a matter that concerns the village or town. The farmer in the village can have and does gain audience with the chief of the town or village as and when need be. The village farmer can and does have audience when need be with the parliamentarian of his or her area during community engagement, funerals, weddings, Sunday service, cultural events and so on. With such multivariate opportunities for interface with members of a given community, it is rather difficult to create the impression through the LEAP program that poverty and relative deprivation automatically lead to exclusion in the case of the extremely poor and for that matter any other group.

It is also accurate and speaking culturally that the society of Ghana does not have an inclusive culture when it comes to people with disabilities. This phenomenon did not happen due to poverty or urbanization or democracy. The culture was wrongly discriminatory towards the disabled and in the unrefined era gone by, looking at the situation through the lens of people with disabilities. In those inglorious days, some national families, mothers and fathers and grandparents even committed criminal acts of infanticide against children born with disabilities such as physical malformations, Down syndrome, and even those faced with intellectual developmental challenges Persons with Disability Act, 2006 (Act 715). The discriminatory tendencies of the nation has not all vanished, even though there is a greater acceptance of people with disabilities today, so long as they are kept out of sight and out of gainful employment. Even today, the 2006 Act on Disability does not make provisions for the protection of children and women with disabilities and does not ensure the political participation of those with disabilities. Therefore, the LEAP policy needs to articulate a cultural specific or relative definition (with all due respect to James Rachels for his exposition on Cultural Ethical Relativism) for entitlement based on disability but not allow a blanket, rather technically and administratively unhelpful designation of disability. What appears to have created the current cohort of the population with extreme poverty in Ghana is, perhaps, attributable to persistent bad government policies since the independence of Ghana in 1957 until this moment (Blank, 1997; 2003). Ineffective and unethical developmental programs egoistically project infrastructural monstrosities that do not contribute to the collective wellbeing of the people of the areas where such projects were built. Over the years, successive governments have combined to disenfranchise the average man and woman of this nation, and have created a permanent state of underclasses, poverty and deprivation across board (Van de Walle, 2001).

\section{Household Economy}

A Ghana Country Case Study report produced by the Oxford Policy Management in conjunction with FAO and the government of Ghana entitled, "Qualita- 
tive Research and analyses of the economic impacts of cash transfer programs in Sub-Saharan Africa, 2013", and its compendium Research Brief also entitled "Impacts of the LEAP program on Community Dynamics in Ghana, 2013" appear to proffer that "the transfer also provided working capital for income earning activities". The report also added that, "depending upon the asset base of the household, this activity ranged from small-scale trading to increasing on-farm productivity, such as hiring labor, purchasing farm assets and inputs. In a few instances, the projects that the beneficiary households were reported to have undertaken under LEAP was even "more ambitious livelihood diversification strategies". The report did not indicate what the "livelihood diversification strategies" were meant to be.

The question is: how can US $\$ 4.00$ a month for a family of four that is already at risk, for a household that is already a subject of chronic poverty, shocks and stresses, be able to spend the transfer sum, and even miraculously manage through voodoo economics, perhaps, and save some of this money to be able to amass enough money to secure a working capital?

In a study conducted by Abbey et al. (2014) and entitled: "Social Interventions Monitoring Project (LEAP monitoring \& beneficiary assessment report", stated that " $80 \%$ of the beneficiaries had no knowledge of the amount due them as at 2014 when the study was conducted." To put it in context, that is 7 solid years since the roll out of the program! Another " $85 \%$ were not aware of the number of times they were to receive the transfer". Abbey et al. (2014) categorically stated that "irregular payments due to delayed receipt of funds at the central level have limited the impact of the transfer". This means that even savings, if at all possible from this fragment, would be difficult to achieve. The Abbey study continued that, due to this very challenge, "beneficiaries were not able to take considered decisions about how to use the transfer-to plan ahead, to invest, to save because of delay in payment of cash" (Abbey et al. 2014: p. 3). Their reportage was more resplendent in its elucidation of the limitations of the program that "majority of the LEAP beneficiaries spent the money received on nutrition, health, and on education" but not on investment activities as proffered by the Oxford/FAO study. On the survival of the beneficiary households as they wait for the next trench of the transfer, about " $56.6 \%$ survived through self-support, $21.6 \%$ obtained family assistance, $11.7 \%$ survived through their own farm/business activities with only $10 \%$ of the recipient households borrowing". The Abbey study calls into questions the eligibility criteria for cash transfer, if the beneficiary households own farms and businesses, have good social networks from family and clan, and own farm assets and other assets. This profile does not fit the definition of those that are considered as extremely poor. Since the local economy impacts relate to the primary issue of the household cash receipts, the questions raised on the uses of that cash transfer have rendered further discussion on the issue of impact mute. The issue of social networks has already been discussed at length. Additional discussion of it would not enhance this paper.

The Differences between LEAP and Sen Approaches 
There appears to be dichotomous purposes between the anticipated outcome of LEAP and Sen's Capability Approach. Whiles Sen's capability approach looks at the functionings of people in terms of what they are able to do for themselves, Ghana's LEAP program looks at the individual's functionings from the point of view of income or wealth. Sen (1985) defined capabilities in a linear progression: from commodity to function or functioning to utility or happiness. He also argued that wealth is not the only thing human beings want and that material things cannot make one happy. They also want other things and therefore cannot use wealth as the denominator to determine the quality of life of all people, since people have different goals and aspirations even within the same perhaps, homogenous society so long as there is equal opportunity for all (Sen, 1992). The conceptualization of poverty alleviation program in and itself is also part of the solution to actual alleviation. Whereas the capability approach looks at the processes or the means that would empower a persons' abilities and capacities to achieve what he wants, LEAP considers the ends, or income and wealth, not job training, not education, not resource centres to help and direct, not decision experts that may advise the beneficiary households on goal setting, but raw cash transfers as the panacea for the alleviation of poverty because it provides instant "wealth".

\section{Functionings and Being in Ghana, Irrespective of Economy Status}

Being or autonomy equals freedom, liberty, self-expression and the capacity to engage in meaningful things that would help to define one's existence (Sen, 1999; 2000; Nussbaum, 2003, (Tocqueville, in Craiutu, 1999). Ghana does not offer the average person such personal, moral, ethical and clean opportunities irrespective of one's best efforts without a benevolent paternal figure or enabler, irrespective of one's level of education and expertise. Mann offered (1986) that,

"Societies are not unitary. They are not social systems (closed or open); they are not totalities. We can never find a single bounded society in geographical or social space. Because there is no system, no totality, there cannot be 'subsystems', 'dimensions', or 'levels' of such a totality. Because there is no whole, social relations cannot be reduced 'ultimately', 'in the last instance', to some systemic property of it-like the 'mode of material production', or the 'cultural' or 'normative system', or the 'form of military organization'. Because there is no bounded totality, it is not helpful to divide social change or conflict into 'endogenous' and 'exogenous' varieties' (Mann, 1986: p. 12).

The ecosystem is skewed to strong man-strong woman influences and involvement in terms of access to competitive jobs and other opportunities, where merit should rule the proceedings (Murray, 1947; Paulsen, 1986). In common usage and language, the nepotistic fervour and activities have been reduced to one word: Protocol. In Ghana when the word "protocol" is used, it is the euphemism for corruption purposefully hatched and executed for the desired outcome. It is a reference to strong, well connected politician or cash laden private person with political reach and who has the ability to influence, for exam- 
ple, university placements and admissions as well as interfere with any competitive process for selection of personnel or candidate for a particular position or role. Such persons undermine and interfere with even secondary school placements and admissions. When it comes to job placements, protocol placement is a powerful tool that can jump the queue and place a blatantly unqualified person ahead of one who is demonstrably qualified and experienced and who has been waiting from dawn to dusk for his or her chance, for his or her foot in the door (UNDP, 1990, 2015; United Nations Sustainable Development Goals, 2015; Ugaz, 2015; Agbodohu \& Quarmyne, 2014; Gockel \& Vormawor, 2004). Being free and autonomous are concepts which do not often occur to the people of this land that it is their birth right (Mann, 1986). The underlying social networks and infrastructure have been drained of their life-support systems of mutual trust, mutual acceptance, the lack of suspicion and community consensus by an overreaching, democratically unsophisticated but powerful and well connected men and women. The people simply assume that they are not entitled to real happiness, and freedoms, and have, by default, turned to excessive religiosity. This kind of situation may lead to limited functionings and lives incorrectly lived (Norman, 2013).

\section{Conclusion}

This paper is about those living on the margin and the community efforts to assist them and guide them to protective lives. Despite the moral and ethical strengthens of the LEAP program, despite the narrative so far, and the reality of living on US $\$ 4.00$ a month by a family of four, it is important to remember that there are government ministers and managers of departments and agencies who ride in SUVs, powered by V8 engines, and air-cooled vehicles. They are fuelled with free government issued fuel coupons. The cost of the vehicles too is something big. The price tag per vehicle is not less than US\$70,000 (Ugaz, 2016; Norman \& Aviisah, 2015).

\section{Recommendation}

1) There is an urgent need to redesign the program, re-articulate the eligibility criteria and to set clear pathways for capacity building of the beneficiary household leaders towards productive activities.

2) The government of Ghana and its development partners need to conduct monitoring and evaluation exercise of the program to assess the contributions, if any, and to inform policy.

\section{References}

Abbey, C. O., Odonkor, E., \& Boateng, D. (2014). Social Interventions Monitoring Project. LEAP Monitoring \& Beneficiary Assessment Report, Accra: African Development Program.

Agbodohu, W., \& Quarmyne, R. C. (2014). Corruption in Ghana: Causes, Consequences and Cures. International Journal of Economics, Finance and Management Sciences, 2, 92-102. https://doi.org/10.11648/j.ijefm.20140201.20 
Amankrah, J. Y. (2016). Youth Unemployment in Ghana: Prospects and Challenges. Assistant Chief Statistician and Head of Labour Statistics, Ghana Statistical Service, Accra: Centre for Economic Policy Analysis.

Association of Ghana Industries (2015).

Barry, B. (1998). Social Exclusion, Social Isolation and the Distribution of Income. CASE/12, Centre for Analysis of Social Exclusion, London: London School of Economics.

Bettinger, F. (1977). How I Raised Myself from Failure to Success in Selling. New York: Simon \& Schuster.

Blakely, E. J., \& Bradshaw, T. K. (2002). Planning Local Economic Development. Thousand Oaks, CA: Sage.

Blank, R. M. (1997). It Takes a Nation: A New Agenda for Fighting Poverty. Princeton NJ: Princeton University Press.

Blank, R. M. (2003). Selecting Among Anti-Poverty Policies: Can an Economics Be Both Critical and Caring? Review of Social Economy, 61, 447-471. https://doi.org/10.1080/0034676032000160949

Bradshaw, T. K. (2000). Complex Community Development Projects: Collaboration, Comprehensive Programs and Community Coalitions in Complex Society. Community Development Journal, 35, 133-145. https://doi.org/10.1093/cdj/35.2.133

Bradshaw, T., \& Muller, B. (2005). Shaping Policy Deccisions with Spatial Analysis. In M. F. Goodchild, \& D. G. Janelle (Eds.), Spatially Integrated Social Science: Examples in Best Practice (pp. 300-322). New York: Oxford University Press.

Brown vs. Board of Education of Topeka (1954). 347 U.S. 483.

Craiutu, A. (1999). Tocqueville and the Political Thought of the French Doctrinaires. History of Political Thought, 20, 456-493.

Durkheim, E. (1895). Rules of Sociological Methods. In R. A. Jones (Ed.), Emile Durkheim: An Introduction to Four Major Works (pp. 60-81). Beverly Hills, CA: Sage Publications. http://durkheim.uchicago.edu/Summaries/rules.html

Estivill, J. (2003). Concepts and Strategies for Combating Social Exclusion: An Overview. Portugal International Labor Office. Journal of Social Policy, 35, 521-523.

FAO/Ghana Country Case Study (2013). Qualitative Research and Analyses of the Economic Impacts of Cash Transfer Programs in Sub-Saharan Africa. Ghana Country Case Study Report, Oxford Policy Management, Rome: Food and Agriculture Organization of the United Nations.

Ghana Health Service 2009 Annual Report (2010).

Ghana Health Service 2010 Annual Report (2011).

Ghana Health Service 2011 Annual Report (2012).

Ghana Health Service 2012 Annual Report (2013).

Ghana Health Service 2014 Annual Report (2015).

Ghana Statistical Service (2010). The Annual Statistical Survey. Accra: Ghana Statistical Service.

Ghana/UNDP Millennium Development Goals Country Report (2015).

Handa, S., Park, M., Darko, R. O., Osei-Akoto, R., Davis, B., \& Diadone, S. (2013). Livelihood Empowerment against Poverty Program Impact Evaluation. Carolina Population Center, Chapel Hill, NC: University of North Carolina.

Harvey, B. (1990). Poverty in the European Community: Final Interim Report of the European Provisional Working Group against Poverty. 
Harvey, B. (1994). Combating Exclusion: Lessons from the Third EU Poverty Program in Ireland, Research and Development Unit, Ireland. Commission of the European Communities, Medium-Term Action Programme to Combat Exclusion and Promote Solidarity: A New Programme to Support and Stimulate Innovation (1994-1999) and Report on the Implementation of the Community Programme for the Social and Economic Integration of the Least Privileged Groups, Brussels: Commission of the European Communities.

www.combatpoverty.ie/publications/LessonsForPolicyAndPractice_1995.pdf

IFRC (2013). Baseline Basics. Planning and Evaluation Department. www.ifrc.org/PageFiles/79595/Baseline\%20Basics\%2010May2013.pdf

IMANI-Ghana. (2016). Monthly LEAP Cash Not Solution to Poverty. www.ghanaweb.com/GhanaHomePage/NewsArchive/Monthly-LEAP-cash

Kulyk, S. (2015). Learn from Ghana's Poverty Alleviation Success Story-Personal Communication. The World Bank Country Co-Ordinator for Ghana, Liberia and Sierra Leone. http://www.graphic.com.gh/news/general-news/

Levitas, R. (2005). The Inclusive Society: Social Exclusion and New Labor. London: Macmillan. https://doi.org/10.1057/9780230511552

Mathieson, J., Popay, J., Enock, E., Escorel, S., Hernandez, M., Johnston, H., \& Rispel, L. (2008). Social Exclusion, Meaning, Measurement and Experience and Links to Health Inequalities: A Review of Literature. WHO Social Exclusion Knowledge Network Background Paper 1, Institute for Health Research, Lancaster, Lancaster University.

Madanipour, A., Cars, G., \& Allen, J. (1998). Social Exclusion in European Cities: Processes, Experiences and Responses. London: Jessica Kingsley.

Mann, M. (1986). The Sources of Social Power. New York: Cambridge University Press. https://doi.org/10.1017/CBO9780511570896

Ministry of Employment and Social Welfare (2012). Department of Social Welfare, Monthly LEAP Cash Payments. Accra: Ministry of Social Welfare and Employment, Ministries.

Ministry of Employment and Social Welfare (2015). Department of Social Welfare DSW, Performance of LEAP 2015. Accra: Ministry of Social Welfare and Employment, Ministries.

Ministry of Employment and Social Welfare (2007).

Murray, C. J. (1947). Separation of Church and State: True and False Concepts. Woodstock Theological Center Library. http://woodstock.georgetown.edu/library/Murray/1947c.htm

Myrdal, G. (1944). An American Dilemma: The Negro Problem and Modern Democracy.

Norman, I. D., \& Aviisah, M. A. (2015). Does Corruption in Ghana Manifest Post Traumatic Stress Disorder? Donnish Journal of Neuroscience and Behavioral Health, 1, 12-20. http://www.donnishjournals.org/djnbh

Norman, I. D., Aviisah, M. A., Awiah, B., Kweku, M., \& Binka, F. N. (2016). The Middle Class Is Synonymous with Corruption in Sub-Sahara Africa. Advances in Applied Sociology, 6, 179-198. http://www.scirp.org/journal/aasoci https://doi.org/10.4236/aasoci.2016.64016

Norman, I. D. (2013). Separation of Church and State: A Study of Accra City's Use of Public Buildings and Schools for Religious Services in Ghana. Advances in Applied Sociology, 3, 282-288. http://www.scirp.org/journal/aasoci https://doi.org/10.4236/aasoci.2013.37036

Norman, I. D., Aikins, M., \& Binka, F. N. (2012a). Traditional and Contrapower Sexual harassment in Public Universities and Professional Training Institutions of Ghana. In- 
ternational Journal of Academic Research, 4, 85-95.

Norman, I. D., Aikins, M., \& Binka, F. N. (2012b). Faith Based Organizations: Sexual Harassment and Health in Accra-Tema Metropolis. Journal of Sexuality and Culture, 14, 1-15.

Nussbaum, M. (2003). Capabilities as Fundamental Entitlements: Sen and Social Justice. Feminist Economics, 9, 33-59. https://doi.org/10.1080/1354570022000077926

Paulsen, M. A. (1986). Religion, Equality, and the Constitution: An Equal Protection Approach to Establishment Clause Adjudication. Notre Dame Law Review, 61, 311-317.

Peace, R. (1999). Surface Tension: Place/Poverty/Policy: From "Poverty" to "Social Exclusion": Implications of Discursive Shifts in European Union Poverty Policy, 1975-1999.

Peace, R. (2001). Social Exclusion: A Concept in Need of Definition. Social Policy Journal of New Zealand, 16, 17-35.

Persons with Disability Act (2006). Act 715. Ghana.

Pritchard, A. E. (2016). IMF Admits Disastrous Love Affair with the Euro and Apologises for the Immolation of Greece.

http://www.telegraph.co.uk/business/2016/07/28/imf-admits-disastrous-love-affair-wit h-euro-apologises-for-the-i/

Rector, R. (2016). Self-Sufficiency, Not Government Spending, Should Be the Measure of Antipoverty Progress.

http://dailysignal.com/2016/03/15/self-sufficiency-not-government-spending-should-b e-the-measure-of-antipoverty-progress/

Schaefer, B. D. (2003). Multilateral Economic Development Efforts in Sub-Sahara Africa. Heritage Foundation No. 858:2003.

Seers, D. (1969). The Meaning of Development. IDS Communication No. 44, 1969, Institute of Development Studies.

Sen, A. (1982). Poverty and Famines: An Essay on Entitlement and Deprivation. http://staging.ilo.org/public/libdoc/ilo/1981/81B09_608_engl.pdf

Sen, A. (1985). Commodities and Capabilities. Amsterdam: Elsevier.

Sen, A. (1993). Capability and Wellbeing. In M. Nussbaum, \& A. Sen (Eds.), The Quality of Life (pp. 30-53). Oxford: Clarendon Press. https://doi.org/10.1093/0198287976.003.0003

Sen, A. (1979). Equality of What? The Tanner Lecture on Human Values, Stanford: Stanford University.

Sen, A. (1987). Ethics and Economics. Oxford: Basil Blackwell.

Sen, A. (1995). Rationality and Social Choice. American Economic Review, 85, 1-24.

Silver, H. (1994). Social Exclusion and Social Solidarity: Three Paradigms of Social Exclusion. International Labor Review, 133, 531-578.

Tandoh, K. (2016). LEAP Household Beneficiaries Receive Payment. Accra: Ghana News Agency.

Ugaz, J. (2015). Corruption Perception Index 2015. Transparency International. http://www.transparency.org/cpi2015

UNDP (1990). Human Development Report. http://www.hdr.org/en/reports/global/hdr1990

UNDP (2015). Human Development Report. http://report.hdr.undp.org

Van de Walle, N. (2001). African Economies and the Politics of Permanent Crisis: 1979-1999 (pp 12-28). Michigan State University, Cambridge: Cambridge University Press.

World Bank/Bank of Ghana Report (2016). Landscape of Jobs in Ghana. 
Submit or recommend next manuscript to SCIRP and we will provide best service for you:

Accepting pre-submission inquiries through Email, Facebook, LinkedIn, Twitter, etc. A wide selection of journals (inclusive of 9 subjects, more than 200 journals)

Providing 24-hour high-quality service

User-friendly online submission system

Fair and swift peer-review system

Efficient typesetting and proofreading procedure

Display of the result of downloads and visits, as well as the number of cited articles Maximum dissemination of your research work

Submit your manuscript at: http://papersubmission.scirp.org/

Or contact aasoci@scirp.org 